
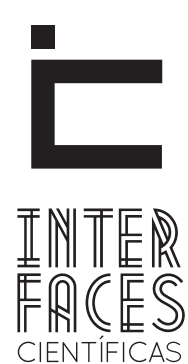

EDUCAÇÃO

ISSN IMPRESSO 2316-333X

E-ISSN 2316-3828

DOI-10.17564/2316-3828.2017v5n2p79-90

\title{
DE LOBINHA A PIONEIRA: SUBJETIVIDADES DE MULHERES NO MOVIMENTO EDUCACIONAL ESCOTEIRO

\section{RESUMO}

Este artigo percorre linhas, como é próprio do método cartográfico, que compõem a presença da mulher no escotismo, pensando nesse percurso as produções de subjetividades. Tem por objetivo cartografar subjetividades de mulheres no movimento escoteiro. Esta é uma pesquisa desenvolvida com três mulheres que participaram e/ou ainda participam desse grupo escoteiro. Durante a pesquisa, foram realizadas entrevistas que produziram falas permeadas de experiências, narrativas, ensinamentos, conceitos de mulher, subjetividades e outros aspectos que compõem a vida dessas mulheres em nossa sociedade. Para pensar a possibi- lidade de uma educação que perpassa a vida e produz subjetividades, foram utilizados autores da Filosofia da Diferença, dentre eles: Deleuze, Foucault e Guattari. No escotismo e em outros dispositivos educacionais, são ensinados valores que conduzem as mulheres a enquadramentos sociais.

\section{PALAVRAS-CHAVE}

Subjetividades. Escotismo. Mulher. 


\section{ABSTRACT}

This article runs through lines, as befits the mapping method, which make up the presence of women in scouting, thinking this way the subjectivity productions. It aims to map subjectivities of women in the scouting movement. This is a research developed with three women who participated and/or participating in this scout group. During the survey, interviews were conducted that produced experiences permeated speeches, narratives, teaching, woman concepts, subjectivities and other aspects that make up the lives of these women in our society. To think of the possibil- ity of an education that permeates life and produces subjectivities, Difference of Philosophy of the authors were used, including: Deleuze, Foucault and Guattari. Scouting and other educational devices are taught values that lead women to social frameworks.

\section{KEYWORDS}

Subjectivities. Scouting. Woman.

\section{RESUMEN}

En este artículo se ejecuta a través de líneas, como corresponde al método de cartografía rizomática, que constituyen la presencia de las mujeres en el movimiento scout, pensando de esta manera las producciones de subjetividad. Se pretende trazar un mapa subjetividades de las mujeres en el movimiento scout. Se trata de una investigación desarrollada con tres mujeres que participaron y/o participantes en este grupo scout. Durante el estudio, se llevaron a cabo entrevistas que produjeron narrativas permeadas de experiencias, de aprendizaje, conceptos mujer, subjetividades y otros aspectos que conforman la vida de estas mujeres en nuestra sociedad. Para pensar en la posibilidad de una educación que impregna la vida y produce subjetividades, han sido elegidos autores de la Filosofia, incluyendo: Deleuze, Foucault y Guattari. En el Movimiento Scout y otros dispositivos educativos se enseñan valores que llevan a las mujeres a los marcos sociales.

\section{PALABRAS CLAVE}

Subjetividad, mujer, movimiento scout, escultismo. 


\section{INTRODUÇ̃̃̃O}

Esta pesquisa aborda aspectos da presença da mulher no movimento educacional escoteiro, pensando o processo de coeducação ${ }^{1}$ e as produções de subjetividades nesse percurso, trabalhando com subjetividades de mulheres que perpassaram o $13^{\circ} \mathrm{Grupo}$ Escoteiro Uirapuru de Sergipe (GEU), desde sua criação, em 1983, até os dias atuais, partindo da questão: como compreender as construções das subjetividades de mulheres no movimento escoteiro?

Apenas recentemente o escotismo passou a ser misto e a promover atividades voltadas a meninos e meninas mutuamente, ou seja, numa ideia de educação voltada a permitir a inter-relação entre homens e mulheres, bem como partisse de princípios de igualdade.

Este texto baseia-se em pesquisa cartográfica desenvolvida com três mulheres que passaram ou ainda participam do Grupo Escoteiro Uirapuru. Em suas falas desvelaram-se experiências, narrativas, signos, elementos educacionais, ensinamentos, conceitos de mulher, subjetividades e diversos outros elementos.

Propomos pensar o conceito de educação não apenas no sentido escolarizado, tendo em vista, todo o legado herdado da modernidade, que nos reafirmou a ideia de que a escola é o lugar para formar o cidadão, o sujeito uno, e muitas vezes nos esquecemos de que educação está na vida.

O movimento escoteiro assim entendido é uma instituição educacional, não escolar. Um território permeado de encontros e desencontros de devires ${ }^{2} \mathrm{e}$

1. 0 conceito de coeducação no escotismo é entendido como "um processo pelo qual meninos e meninas, rapazes e moças vivenciam um plano educacional para um melhor e mais harmônico desenvolvimento da personalidade, favorecendo a educação recíproca de uns pelos outros e levando em consideração as realidades locais e pessoais. Isto tendo presente os fins e o método do Escotismo. A coeducação não é, portanto, simplesmente uma questão de reunir crianças e jovens de ambos os sexos" (SUFFERT, 1980, p. 5)

2. Quanto ao devir Deleuze e Guattari $(1997$, p.19) indicam que "é um rizoma, não uma árvore classificatória nem genealógica. Devir não é cer- multiplicidades ${ }^{3}$. Estes se compõem em movimentos que são de aprendências e ensinâncias, que estão sempre em processo de construção, produzindo outros movimentos, subjetividades, novos conhecimentos, ou seja, educação é termo muito mais amplo do que nos foi e é ensinado.

Aqui compreendemos, enquanto aprendências e ensinâncias, como algo que está acontecendo, não como uma ideia pronta e acabada de formar, e está pronto, como um produto. A educação tem sido confundida com uma prateleira onde se adquire conhecimento. Entretanto, esse movimento entre o aprender e ensinar é de inusitados encontros com as multiplicidades, que nos perpassam e nos modificam.

\section{A ABORDAGEM CARTOGRÁFICA}

Neste estudo, fazemos uma abordagem cartográfica. Entendendo que esta perspectiva de análise permite compor um processo de pesquisa, que compreenda as subjetividades dos sujeitos, a partir dos elementos do sensível e demais impressões que permeiam o social.

No campo empírico, neste caso foi grupo escoteiro estudado, coletamos dados e impressões que auxiliassem nas análises. Procedemos com dois blocos de entrevistas com três mulheres que passaram ou ainda participam do GEU, que foram lobinhas, esco-

tamente imitar, nem identificar-se; nem regredir - progredir; nem corresponder, instaurar relações correspondentes; nem produzir, produzir uma filiação, produzir por filiação. Devir é um verbo tendo toda sua consistência; ele não se reduz, ele não nos conduz a 'parecer', nem 'ser', nem 'equivaler', nem 'produzir'".

3. Para Deleuze e Guattari (1997, p.27), uma multiplicidade "se define, não pelos elementos que a compõem em extensão, nem pelas características que a compõem em compreensão, mas pelas linhas e dimensões que ela comporta em 'intenção"'. 
teiras, guias, pioneiras ou chefes ${ }^{4}$. Estas entrevistas foram semiestruturadas e tinham um roteiro voltado a questões acerca das experiências dessas mulheres com o movimento escoteiro, sobre as atividades, as características, os signos, os elementos educacionais, os ensinamentos, os conceitos de mulher e alguns outros questionamentos que acabaram por ocorrer neste percurso.

Esta abordagem empírica tem por objetivo identificar, a partir da análise de falas, conceitos presentes que indiquem valores passados do movimento escoteiro para essas mulheres, que compõe uma moralidade, e, que subjetiva essas mulheres numa "ideia de uma subjetividade de natureza industrial, maquínica, ou seja, essencialmente fabricada, modelada, recebida, consumida" (GUATTARI; ROLNIK, 2010, p. 33). Visto que, a análise a partir do método cartográfico "não tem nada a ver com explicar e muito menos revelar" como nos propunha o Iluminismo (ROLNIK, 1989, p. 3). Afinal, a cartografia permite mapear essas experiências com o escotismo, que são variantes e moventes a todo tempo.

O processo de produção de subjetividades atua de forma a fabricar modelos de ser homem ou mulher, como lidar com o corpo, com as formas de se compreender e o olhar para o outro, e, mais especialmente a relação consigo. Na contemporaneidade se fabricam subjetividades em escala mundial, e essa produção maquínica atua, também, nas delimitações do tempo, mexendo com os entendimentos do que seja passado, presente e futuro.

Portanto, a produção de subjetividades de mulheres no movimento escoteiro e os conceitos produzidos do que ser e como se compreender, estão em proces-

4. As unidades escoteiras compõem ramos distintos delimitados por faixa etária. As alcateias comportam lobinhos e lobinhas de 6,5 a 11 anos. As tropas escoteiras são compostas de escoteiras e escoteiros de 11 a 15 anos. As tropas seniores agregam jovens seniores e guias de 15 a 18 anos. Os clãs pioneiros compõem-se de pioneiros e pioneiras de 18 a 21 anos. As idades posteriores são de membros voluntários que podem ser chefes, assistentes, dirigentes ou que ocupem qualquer função de apoio ao Grupo Escoteiro. so, traçando linhas em um emaranhado, sem início, nem fim, sempre acionando pelo meio e compondo um plano de imanência, em um processo de investigação da produção de subjetividades.

\section{A COEDUCAÇ̃̃O NO MOVIMENTO ESCOTEIRO}

O escotismo é um movimento educacional, não escolar, voluntário, criado pelo inglês Baden-Powell (1857-1941), em 1907, com uma proposta de atividades destinada a meninos. Entretanto, em pouco tempo de fundação muitos grupos de escoteiros foram se formando na Europa, e em outras partes do mundo, chegando ao Brasil em 1910. O movimento que se espalhou rapidamente, logo despertou o interesse de meninas para o ingresso nas tropas escoteiras. Em 1910, foram criadas as primeiras Companhias de Guias, pelo mesmo fundador do escotismo, dando início ao movimento bandeirante, paralelo ao escotismo, mas destinado somente a meninas.

Escoteiros e bandeirantes vão constituir-se em dois movimentos, o primeiro destinado a meninos, o outro a meninas, até que o processo de coeducação estabeleceu educação mista para ambos. O tema coeducação entrou nas discussões das conferências mundiais escoteiras na segunda metade da década de 1970, resultado da instituição das escolas mistas no ensino escolarizado.

Entre os anos de 1979 a 1985 a União dos Escoteiros do Brasil (UEB) iniciou a implantação do processo de coeducação no movimento escoteiro. Com isso, passou aos poucos a atuar com seções mistas. Hoje, o escotismo é o maior movimento de educação não escolar do mundo, está presente em 160 países, das mais diversificadas composições culturais, étnicas, religiosas, geográficas e diversas outras multiplicidades, com cerca de 28 milhões de jovens, e agrega cerca de 60000 membros juvenis no Brasil (ESCOTEIROS..., ON-LINE). 
Atualmente, o Princípios, Organização e Regras (POR) da UEB permite a existência de grupos, patruIhas ou matilhas apenas para meninas ou meninos. $E$ facultativo a cada grupo abrir espaço para as mulheres. Ainda existem grupos que não permitem a entrada de meninas ou que as separam tropas e patrulhas, o que acaba por continuar em um pensamento de exclusão da diferença, e existem muitos espaços no movimento escoteiro que a mulher não tem ocupado.

Compreendemos o escotismo como um movimento educativo, se modificando e às vezes, permanecendo com preceitos que tendem a agir como norma. É uma educação para além da forma como o conceito moderno concebeu, permeia toda a vida, todas as capacidades que nos compõe, conhecidas ou não. 0 escotismo é um movimento para os jovens, segundo suas próprias definições, em que adultos colaboram de forma voluntária, contribuído com o desenvolvimento de jovens.

\section{EXPERIÊNCIAS QUE PERPASSAM AS SUBJETIVIDADES DAS MULHERES NO ESCOTISMO}

Iniciamos as entrevistas, pensando em três mulheres, para elas demos nomes relacionados a elementos do escotismo Raksha, Akelá e Lis. Nessas três fomos encontrando multiplicidades, outras mulheres em nossas conversas. São subjetividades nômades de mulheres, meninas, mães, esposas, chefes, Akelás, filhas, irmãs, lobinhas, escoteiras, guias, pioneiras, aventureiras, flores de lis, e outras tantas.

A primeira dessas mulheres é Raksha ${ }^{5}$, que passou por todos os ramos do escotismo até ser chefe, o que

5. Refere-se a mãe loba da história de Rudyard Kipling no livro da Jângal (2002), em que Raksha cuida de Mowgli, junto com seus filhotes lobinhos. Esta literatura é utilizada como fundo de cena nas alcateias do movimento escoteiro. não é frequente no escotismo. Ela é a mãe loba, uma mulher e a intensidade de ser mãe; foi lobinha, escoteira, guia, pioneira, chefe, e hoje dedica-se a cuidar da cria.

A segunda é Akelá que para a alcateia de lobos é a chefe, no escotismo nunca foi membro juvenil, mas é uma docente da vida, com ensinamentos, aprendizados e experiência de uma vida dedicada ao movimento. Ela é chefe de escoteiros no GEU. É voluntária do movimento há 26 anos, e nunca foi membro juvenil, já entrou como assistente de alcatéia; como chefe ensina e aprende tantas coisas.

A terceira, Lis, uma ex-escoteira carrega consigo o elemento que poucos conseguiram, é lis de ouro, uma das conquistas mais desejadas pelos escoteiros e escoteiras.

As experiências estão perpassando a construção das subjetividades dessas mulheres de tal forma que trazem em suas falas os encontros que vivenciaram no escotismo, quando questionadas por situação similar apresentam experiências singulares. Visto que, "a experiência, a possibilidade de que algo nos aconteça ou nos toque, requer um gesto de interrupção, um gesto que é quase impossível nos tempos que correm" (LARROSA, 2001, p. 7). Desses primeiros momentos com o movimento escoteiro, na fala de Lis ela apresenta um pouco da ideia que o escotismo passa de aventura, de desbravar e participar do grande jogo, quando ela diz que,

Imagina uma tropa de meninas com um bastão na mão,
que na minha época chamava bastão, não sei se chama
assim agora. Uma tropa de meninas. Era mágico. Era
uma coisa radiante, porque você sair, se deslocar para
Catedral, andando e cantarolando. Canções que na épo-
ca da primeira reunião não sabia e não conhecia. E a
gente ir brincar, de uma forma espontânea, sem com-
promisso, passar uma tarde realmente de lazer. ${ }^{6}$

Entre as experiências nos diversos ramos do movimento algumas marcaram a singularidade de cada

6. Entrevista com Lis no dia 28/11/2011. 
uma dessas mulheres. Para Raksha uma das coisas que mais the marcou no movimento foi o momento de passagem da tropa escoteira para tropa sênior. A passagem costuma marcar uma mudança importante para o membro juvenil, ele deixa o ramo, que por vezes passou anos de sua vida, segue para outro, com atividades diferenciadas do anterior, e apresenta ao escoteiro a difícil tarefa de crescer e reconhecer essa mudança. Em suas lembranças sobre este momento ela diz que,

No ramo sênior eu lembro de uma atividade que foi uma passagem do ramo escoteiro para o ramo sênior foi uma atividade que agente tinha que caminhar com mochila com as coisas todas da gente até um sitio do chefe na época. E eu tive a primeira noite com os mais velhos do que eu. Eu era só escoteira e estava fazendo a passagem pra ser guia. Então assim eu tava muito acanhada, tudo assim tudo maiores e eu uma escoteira no meio deles. Nessa minha passagem, eu tava assim num terreno muito dificultoso pra mim, porque assim eles já tinham experiência e aquilo tava começando pra mim. ${ }^{7}$

Para Akelá, as experiências que lhe perpassam têm muita relação com as que atravessam seus lobinhos e escoteiros. São momentos que marcam o campo do sensível, são marcas, vestígios, singularidades, encontros, que nessas entrevistas estão a percorrer sua fala.

A grande experiência minha, a primeira grande experiência é a promessa. Então, toda vez que eu faço uma promessa com um menino parece que eu to fazendo minha promessa. Então foi minha grande experiência, foi assim minha grande emoção no movimento escoteiro foi minha própria promessa. E depois cada conquista dos meninos é como se eu tivesse conquistando também. Então cada Cruzeiro do Sul que eles conquistaram, cada lis de ouro que os meninos conquistaram, cada especialidade e cada pequena coisa que os meninos conquistam, desde acender a fogueira quando eu vejo a felicidade deles acendendo a fogueira. Então assim as pequenas conquistas. E o que me emociona assim, eu tinha assim eu me sinto com dever cumprido quando encontro hoje meus ex-lobinhos, meus ex-escoteiros dizer o quanto o movimento escoteiro ajudou eles, o quanto foi bom eles terem sido escoteiros. ${ }^{8}$
Mãe Loba ingressou no movimento escoteiro com seu irmão mais novo, por influência de um amigo de seu pai que era chefe no GEU. Gostou, ficou por mais de dez anos no escotismo, passou de lobinha até chegar a ser chefe escoteira.

Akelá, como dito, não foi membro juvenil. Seu irmão fazia parte do movimento que ainda era somente para homens. Com a necessidade de uma chefe muIher seu irmão a chamou para a substituição. Sempre quis fazer parte do movimento escoteiro, quando pequena não quis ser bandeirante. Jovem queria fazer parte do Clã Misto do Uirapuru, mas não conseguiu entrar porque era um grupo muito fechado. Quando o grupo precisou de mulheres para a Alcateia ela foi convidada. No da entrevista conta que,

Quando eu entrei a alcateia era só de meninos, depois quando a gente fez a coeducação eram só meninos, eram bem poucos, agora não lembro quantas crianças tinham. Eu sei que eram bem poucas. Eu não sabia nada de movimento escoteiro. Não tinha a facilidade de internet, de livros, não tinha nada. Eu entrei com a cara e a coragem e fui aprendendo na marra, na tora mesmo. Eu vim fazer curso, nem lembro quando, só sei que foi depois de dois ou três anos, depois que vim fazer curso. E assim acho que agora eu analisando, eu acho que os lobinhos, os meus primeiros lobinhos eles pegaram uma pessoa inexperiente que não sabia nada do movimento escoteiro, eu acho que eu acabei prejudicando alguém, assim com especialidade. ${ }^{9}$

Lis foi convidada para o movimento por uma colega de escola e vizinha, quando tinha mais ou menos 11 anos. Foi preciso convencer sua mãe de que era uma atividade séria. A ida ao grupo era um momento de liberdade, já que seus pais não a deixavam sair muito. Por isso, o escotismo foi encantador à menina aventureira. Com o tempo sua irmã mais nova e colegas da escola foram integrando o movimento. Quando saiu do movimento estava na tropa sênior com aproximadamente 17 anos.
7. Entrevista com Raksha no dia 09/10/2011.

8. Entrevista com Akelá dia 11/10/2011.
9. Entrevista com Akelá dia 01/06/2012. 
Portanto, pensar as subjetividades dessas mulheres no território do escotismo perpassa por compreender a experiência de cada uma com o movimento. Essas experiências têm mostrado o tanto de inusitado que se encontram nas atividades escoteiras, que diferem dos modelos constituídos e pensados para o escotismo. As mulheres entrevistadas apresentaram possibilidades e movimentos que sem suas experiências e singularidades não poderiam encontrar.

\section{1 SUBJETIVIDADES DE MULHERES ESCOTEIRAS}

Nesse grande jogo do escotismo, um território educacional, conhecimentos, fundamentos e valores são ensinados e aprendidos, os quais produzem marcas. Tratamos aqui das possíveis que constroem subjetividades de mulheres no movimento escoteiro; são linhas que elas atravessam. As palavras de ordem estão a construir discursivamente essa subjetivação, pois no escotismo se produz subjetividades específicas, mas não delimitadas, finitas, muito pelo contrário, são permeadas de multiplicidades. Existem linhas de fuga, é o que possibilita a potência do desejo de agir. Afinal, as mulheres estão prenhas de multiplicidades $^{10}$, de linhas, segmentariedades duras e binárias, estratos, territorialidades, linhas de fuga e movimentos de desterritorializações.

Toda a ação que está organizando as materialidades de nossa sociedade produz subjetividades. Toda a subjetividade é coletiva e singular e todo o movimento, todo o deslocamento e afecções produzem subjetividades. Uma ação pode produzir agenciamentos desta subjetividade assim como suas linhas de fuga; são ações que

10. Quanto à questão das multiplicidades e dos processos de subjetivação Deleuze e Guattari $(1995$, p. 8$)$ indicam que "as multiplicidades são a própria realidade, e não supõe nenhuma unidade, não entram em nenhuma realidade, e tampouco remetem a um sujeito. As subjetivações, as totalizações, as unificações são, ao contrário, processos que se produzem e aparecem nas multiplicidades. Os princípios característicos das multiplicidades concernem a seus elementos, que são singularidades; as suas relações, que são devires; a seus acontecimentos, que são hecceidades (quer dizer, individuações sem sujeitos); a seus espaços-tempos, que são espaços e tempos livres; a seu modelo de realização, que é rizoma (por oposição ao modelo da árvore); e seu plano de composição, que constitui platôs (zonas de intensidades contínua); aos vetores que as atravessam, e que constituem territórios e graus de desterritorialização". produzem o tempo e todo o tempo estamos atravessados por ambas as linhas e mais ainda outras mais. (FELDENS, 2008, p. 83).

A diferença, a singularidade e a criação resistem aos enquadramentos. Essas mulheres por vezes fogem dos enquadramentos sociais feitos à mulher, quando Lis saudosa me diz "eu já sou meio garotona, gostava de folia, dessas coisas de menina aventureira" ${ }^{11}$. No decorrer da fala, a moral começa a pesar sobre as linhas de composição, decomposição e destino da mulher, se impõe sob a subjetividade mulher-garota-menina-aventureira, e Lis completa com: "o movimento escoteiro precisa da mulher, para passar o ensinamento que a gente teve e pode passar para nossos filhos, os nossos maridos, para nossas irmãs e o futuro vem ai”. Entretanto, nós mulheres não podemos esquecer que "mulheres não tem destino, fadário. Mulheres multiplicam as linhas, centenas, milhares, infinitas; mulheres são devir; devir mulher" (FELDENS, 1999, p. 86).

Essas subjetividades estão sendo fabricadas no escotismo, em uma multiplicidade de agenciamentos com diversos elementos que estão a nos afectar, produzindo sempre outras e infinitas afecções. As linhas de fuga possibilitam romper as raízes e iniciar diversas outras ligações. Nessa incessante construção, a subjetividade não é total ou única, por isso desliza em nossas mãos. Akelá diz que "como a gente muda, o mundo inteiro muda. Então, a gente... eu não posso ser sempre a mesma pessoa" ${ }^{12}$, por isso lidamos com mulheres, três delas e ao mesmo tempo muitas.

Raksha, Akelá e Lis estão nesse plano de multiplicidades, o escotismo promove intersecções entre elas. Buscamos nelas conceitos de mulher, traços, vestígios, algumas linhas. Os conceitos vieram carregados pelas suas subjetividades. Para Raksha, a ideia que o escotismo passa é de ser apenas para meninos, e que a mulher tem que se identificar com as atividades.

11. Entrevista com Lis no dia 02/06/2012.

12. Entrevista com Akelá dia 11/10/2011. 
Olha... quando eu entrei tinha assim bastante menina, assim é meio complicado. Na alcateia eu lembro de que tinha poucas meninas eram mais meninos. Então o movimento é mais visado pra homens. Mais assim de um tempo pra cá, de muitos anos atrás foi acrescentando mulheres, mas pelo o que eu entendi quando eu entrei o Uirapuru, o Universal na época foi o que colocou as meninas primeiro, foi o que acolheu as meninas. Porque todos os grupos da região de Sergipe só tinha meninos e ninguém aceitava meninas. Ai eu não sei como foi a conversa que os chefes tiveram, que decidiram aceitar as meninas. Então, o Uirapuru foi um grupo da região de Sergipe que começou a acoIher as meninas. Então, toda menina que queria ser escoteira, ou lobinha que seja, seguia para um grupo que só recebia menino ai indicava. Vá pro Universal, o atual Uirapuru que agora eles aceitam meninas, ai assim por ser uma aceitação maior, ai acho que os outros começaram a ter meninas. Assim eu já cheguei a ver, assim quando era lobinha cheguei a ver uma ou duas em outros grupos também, mas assim pra ter amizade feminina era muito difícil porque não é toda menina que gosta desse tipo assim, de ficar no mato. De atividade não é pesada, né? Mas de aventura isso e aquilo outro é pra quem gosta mesmo. ${ }^{13}$

Sua concepção de mulher perpassa por sua experiência com o movimento escoteiro, carrega junto modelos de ser para menino e menina, afirmando que essas atribuições fazem com que o escotismo seja visto como um território de meninos. É uma construção que faz com que se produza socialmente e culturalmente demarcações. Também é resultante da recente relação do movimento escoteiro com a presença de mulheres. Isso porque ainda se permite a existência de grupos, patrulhas ou tropas apenas para meninas ou meninos.

Cada grupo pode escolher pela inserção ou não de mulheres. E não é raro encontrar grupos apenas com meninos, por escolha, ou até mesmo pela dificuldade de possibilitar a entrada de meninas no movimento. Suas atividades igualmente quebram muito com o padrão de atividades que podem ser desenvolvidas por meninas. Por conta disso a construção discursiva que trata do movimento escoteiro tende a compreendê-lo como um território de meninos. Ainda é um problema para o movimento a questão da entrada de mulheres, o que acaba por potencializar a eliminação da diferença, visto que não é problemático apenas para mulheres, mas para toda a multiplicidade que não consegue entrar ou permanecer em um grupo escoteiro.

Eu assim, eu sempre gostei. Eu só fui assim, uma primeira vez num acampamento e fiquei com aquilo, mas... a mulher tem que se identificar na questão da coisa toda. Porque menino já gosta de subir em árvore, isso e aquilo outro, menina gosta de ficar mais calma, mais tranqüila. Eu vejo assim. Na época eu via poucas meninas, mas tinha muitas escoteiras que eu via e muitas guias também, quando eu era lobinha ${ }^{14}$.

Neste caso apresenta-se um elemento que é a dificuldade do movimento escoteiro em ser atrativo para meninas. Acaba por se construir uma subjetividade menina aventureira e moleca que não são e nem comportam culturalmente o conceito estabelecido para menina.

A escoteira-mulher está por desterritorializar a concepção de escotismo como lugar de homem. Sua presença em tropas vai minando a existência de um território apenas de homens. Entretanto, ainda permanecem os conceitos sociais que agem a enquadrar homens e mulheres, lembremos que os enquadramentos nem sempre objetivam um mesmo fim. Os movimentos que enquadram podem nos confundir. $\mathrm{Na}$ mesma fala que Akelá afirma a potencialidade ativa da mulher no movimento, ela também repete a ideia do elemento maternal atrelado à mulher.

Eu acho que a mulher tem a mesma importância que o homem no movimento escoteiro e não me sinto, nem nunca me senti discriminada, por ser mulher. Eu já fui assim pra cursos, praticamente só tinha eu de mulher, pra reuniões, cursos não reuniões, eu nunca me senti discriminada não, eu tive as mesmas oportunidades que os homens tem. Eu sou a terceira... só existiu três insígnias da madeira em Sergipe. Eu nunca senti não acho que a gente tem a mesma importância e pra o lobinho é até melhor. Eu acho que os lobinhos, eles se identificam mais com a chefe feminina, com a chefe

13. Entrevista com Raksha no dia 01/06/2012.

14. Entrevista com Raksha no dia 09/10/2011. 
mulher do que com o homem, eu acho assim, eu tenho essa opinião, eu acho que pelo lado maternal da mulher, não sei, o lobinho se identifica mais com a mulher. Isso eu vejo lá no grupo os lobinhos ficam mais comigo e com a chefe, e faz pergunta mais pra gente mesmo eu não sendo chefe de lobinhos. Eles tem uma aproximação mais comigo do que com o chefe homem, mesmo os meninos apesar dele brincar com ele, eles não tem essa aproximação $0^{15}$.

No decorrer da fala ela apresenta um conceito de mulher forte e independente. Essa mulher desvia ao dever ser, ela desliza dos labirintos pré-traçados. "Não somos, portanto, nem maiores nem menores do que nós mesmos, somos o que inventamos para sermos e, nesta medida, somos potencialmente senhores da vida" (FELDENS, 2008, p. 41). A chefe escoteira Akelá leva para sua tropa seu entendimento de que a muther pode fazer as mesmas coisas que os homens, mas acaba, esbarrando também, por vezes, em enquadramentos que as meninas já trazem de suas experiências fora do grupo, ou até mesmo que possa ter tido algum acontecimento que as levou a pensar dessa forma na própria tropa escoteira.

Como no momento de sua fala Akelá diz que nem sempre as meninas gostam de jogar futebol, isso pode ser também por palavras sutis dos meninos as desaconselhando a jogar.

$\mathrm{Na}$ época que eu entrei no movimento tem pessoas que é só assistente só assiste, tinha gente que só fazia assistir, então muitas mulheres, as próprias mulheres é que se discriminam. Ah, eu sou mulher então não vou pegar peso. Ah, eu sou mulher não vou fazer isso. Gente pegue essa barraca que tá pesada. Então como eu nunca fiz isso, talvez por isso me trataram sempre de igual pra igual. Eu nunca fui nenhuma fresca. Entre aspas. Então, eu nunca fiz isso também na minha tropa. $\mathrm{Na}$ minha tropa meninos e meninas fazem as mesmas coisas. As meninas vão pegar lenha pra fazer fogueira, os meninos lavam pratos, os meninos cozinham. 0 tratamento é igual. Então, eu nunca disse a menina: você não pode porque você é menina. As meninas jogam bola, apesar que não gostam muito, o que faço com os meninos eu faço com as meninas. Quem acaba

15. Entrevista com Akelá dia 11/10/2011. se discriminando é a própria mulher. Porque a mulher quer ser muito independente, mas quer que o homem puxe a cadeira pra ela, e pague as contas todas pra ela. Então, como ela quer ser independente e ao mesmo tempo dependente do homem. Eu não sei se é porque eu sou assim eu sempre tive essa visão de querer fazer as coisas, não querer que ninguém faça por mim. Isso eu aprendi até com o movimento escoteiro antes de ser escoteira ${ }^{16}$.

O escotismo produz subjetividades de mulheres. Ao passo em que elas ganham independência e vão conduzindo ações que culturalmente não eram para elas, ao mesmo tempo essa mulher tem que ser muther de um homem e mãe de outro, que vai cuidar e apresentá-lo um modelo do "bom cidadão". Essa é uma interferência subjetiva da sociedade patriarcal, como de induzir comportamentos. Lis, em entrevista no dia 28 de novembro de 2011 indica essas variações no seu conceito de mulher:

\begin{abstract}
Ser mulher no movimento eu acho que é você quebrar muitos tabus. Você mostrar que você pode conseguir muitas coisas assim. Você pode mostrar que você... É complicado viu... Ser mulher é mostrar que você pode, independente de sexo, de força física, independente de que você tem seu lado feminino e pode mostrar muita coisa, contribuir, quantas atividades que a gente fez e colocou nosso toque feminino. E o movimento escoteiro precisa da mulher, para passar o ensinamento que a gente teve e poder passar para nossos filhos, os nossos maridos, para nossas irmãs e o futuro vem ai. Tudo que eu aprendi no sentido de cidadania, de família, de religião, isso tudo você aprende no movimento escoteiro.
\end{abstract}

O processo de produção de subjetividades atua de forma a compor modelos de ser homem ou mulher no escotismo, de compor jovens entre meninos e meninas cidadãos. É dificultoso produzir linhas de fuga no emaranhado movimento maquínico de subjetivação. A produção de subjetividade é a matéria-prima das forças que induzem os enquadramentos. 0 poder está em todos os lugares, é múltiplo e age sutilmente. "Quem exerce o poder deve se situar num campo de relações complexas onde ocupa um ponto de transição: seu status pode tê-lo colocado ali, mas não é esse

16. Entrevista com Akelá dia 01/06/2012. 
status que fixa as regras a serem seguidas e os limites a serem observados" (FOUCAULT, 1985, p. 95).

0 momento em que o escotismo abriu a possibilidade para entrada de meninas, a sociedade não via aquele como um lugar para elas, como outros territórios, um dia também foi a escola, a universidade, o mundo do trabalho, o público e o fora do lar. Carregamos um pensamento patriarcal que vê a mulher e não concebe que meninas possam construir autonomia, acampar, liderar, romper com enquadramentos tão impostos e acionados para perpetuar uma espécie de superioridade dos homens em relação às mulheres.

\section{CONSIDERAÇÕES FINAIS}

Com este estudo passamos a compreender que o problema da inclusão da mulher entre os escoteiros perpassa pelo entendimento de que não devemos partir dessas construções culturais já postas e perpetuadas do que é ser homem ou mulher. Essa divisão é o próprio cerne da discussão, porque exclui a diferença, o outro desviante desse enquadramento. 0 escotismo é um encontro de singularidades,

[...] cada singularidade é a dobra do eu no outro e do outro no eu. 0 processo educativo, assim, só pode ser imanente, relativo ao grupo e dependente daquele grupo, sendo irrepetível. Ou melhor, uma experiência educativa assim pensada pode ser repetida, mas gerará diferença, não o mesmo. (GALLO, 2012, p.15).

Educação, essa é uma palavra que tenho insistido e que não comporta princípios de desigualdade, delimitação de acesso ou não. Está em movimento, promovendo encontros, são linhas que atravessam entre o aprender e ensinar, o ensinar e aprender, e outras possibilidades. Se ainda falamos e discutimos as velhas questões de gênero, entre o masculino e o feminino, continuamos a queimar sutiãs e a alimentar revoltas, é porque não conseguimos enxergar as ilimi- tadas diferenças que nos perpassam e nos encontram. A mulher é apenas a porta de entrada do pluriverso de multiplicidades.

Afinal, cada criança traz da vida além do grupo escoteiro, muitas experiências que as compõe. Em suas diferenças, apresentam-se como múltiplos. Muitas coisas os influenciam, a família, a escola, a vida social, as diversas experiências que adquiriram e que são levadas ao pluriverso educacional do escotismo. Um chefe escoteiro, lidando com a juventude não pode continuar a repetir concentidamente um dos maiores problemas da educação, que é confundir o aprender com a aquisição de conteúdos, em que se desconsidera a experiência. Entretanto, se a experiência é aquilo que nos toca, nos faz diferentes, pois os processos educativos precisam nos tocar para que haja movimentações no pensar.

As experiências dessas mulheres nos indicam como não podemos conceber na educação espaços separatistas e segregadores. 0 território do escotismo tem que proporcionar aos jovens um espaço educacional propício ao seu desenvolvimento, favorecendo a educação recíproca de uns pelos outros, levando em consideração as realidades locais e pessoais. Não podemos continuar a enquadrar o outro no nosso modelo do que ser e o que não ser. Essas delimitações sociais e culturais só agem em prol da exclusão da diferença. Mulher é: vida, multiplicidade, força e devir mulher.

\section{REFERÊNCIAS}

BADEN-POWELL, Robert Stephenson Smyth. Girl

guiding: para fadas, bandeirantes, guias e chefes. Rio de Janeiro: Federação das Bandeirantes do Brasil - FBB, 1955.

BALLESTEROS, Bernardo A. Documento I: Escotismo e Coeducação - (Presidente da Comissão Interamericana de Programa). Sempre alerta: 
Informativo da União dos Escoteiros do Brasil. Brasília: UEB, novembro/dezembro, n.64, 1980.

DELEUZE, Gilles; GUATTARI, Félix. Mil platôs: capitalismo e esquizofrenia. V.2. São Paulo: 34, 1995.

DELEUZE, Gilles; GUATTARI, Félix. Mil Platôs: capitalismo e esquizofrenia. Trad. Suely Rolnik. V.4. São Paula: 34, 1997.

DELEUZE, Gilles; PARNET, Claire. Diálogos. Lisboa: Relógio D’Água, 2004.

ESCOTEIROS DO BRASIL - Construindo um mundo melhor. Institucional. Disponível em: <http://www. escoteiros.org.br/institucional/>. Acesso em: 14 maio 2011.

FELDENS, Dinamara Garcia. Cartografias da ditadura e suas moralidades: os seres que aprendemos a ser. Maceió: EDUFAL, 2008.

FELDENS, Dinamara Garcia. Luízas, Rosas, Bias e Joanas: subjetividades femininas na Vila Santo Antônio. 1999. Dissertação (Mestrado em Educação) - São Leopoldo: Universidade do Vale do Rio dos Sinos, 1999.

FOUCAULT, Michel. História da sexualidade 1: a vontade de saber. Lisboa: Relógio D’Água Editores, 1994b.

FOUCAULT, Michel. História da sexualidade 3: 0 cuidado de si. Rio de Janeiro: Graal, 1985.

FOUCAULT, Michel. Vigiar e punir: nascimento da prisão. Trad. Raquel Ramalhete. Petrópolis: Vozes, 1987.

GALLO, Silvio. Eu o outro e tantos outros: educação, alteridade e filosofia da diferença. Disponível em:
<www.grupodec.net.br/ebooks/GalloEuOutroOutros. pdf>. Acesso em: 20 jan. 2012.

GUATTARI, Félix; ROLNIK, Suely. Micropolítica: cartografias do desejo. 10.ed. Petrópolis-RJ: Vozes, 2010.

KIPLING, Rudyard. 0 livro da Jângal. Trad. Monteiro Lobato. Porto Alegre-RS: UEB/RS, 2002.

KOHAN, W.O. "O que pode um professor?". In: KOHAN, W.O. Deleuze pensa a educação, Segmento, 2007. p.48-57.

LARROSA, Jorge. Notas sobre a experiência e o saber de experiência. Palestra proferida no $13^{\circ} \mathrm{COLE}$ Congresso de Leitura do Brasil, realizado na UNICAMP, Campinas-SP, no período de 17 a 20 de julho de 2001.

ROLNIK, Suely. Cartografia Sentimental: transformações contemporâneas do desejo. São Paulo: Estação Liberdade, 1989.

ROLNIK, Suely. Guerra dos gêneros \& Guerra aos gêneros. Disponível em: <http:caosmose.net/ suelyrolnik/pdf/genero.pdf>. Acesso em: 14 maio 2011.

SUFFERT, Rubem. A coeducação na região interamericana. Sempre Alerta: Informativo da União dos Escoteiros do Brasil. Brasília: UEB, novembro/dezembro, 1980.

UNIÃO dos Escoteiros do Brasil - UEB. Documento II: A Coeducação Do Brasil. Sempre Alerta: Informativo da União dos Escoteiros do Brasil. Brasília: UEB, n.79, julho-agosto, 1982

UNIÃO dos Escoteiros do Brasil - UEB. POR Princípios, Organização e Regras. Curitiba: Nacional, 2008. 
1. Doutora em Educação pela UNISINOS; Professora da Universidade Federal de Sergipe - UFS; Coordenadora do Grupo de Pesquisa Educação, Cultura e Subjetividades - GPECS/CNPq/UFS. Email: dfeldens@hotmail.com 2. Doutoranda em Educação pela Universidade Tiradentes - UNIT; Tem suas

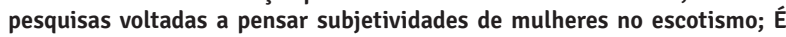
Avaliado em: 19 de dezembro de 2016 Aceito em: 22 de dezembro de 2016 pesquisadora integrante do Grupo de Pesquisa Educação, Cultura e Subjetividades - GPECS/UNIT/CNPq. Email: aldenisecs@yahoo.com.br 